\title{
Structure-activity Relationships of Neoechinulin A Analogues with Cytoprotection against Peroxynitrite-induced PC12 Cell Death
}

\author{
Kuniaki Kimoto, Toshiaki Aoki, Yasushi Shibata, Shinji Kamisuki, Fumio Sugawara, \\ Kouji Kuramochi, Atsuo Nakazaki, Susumu Kobayashi, Kenji Kuroiwa, \\ Nobuo Watanabe, Takao Arai
}

Received: August 17, 2007 / Accepted: September 6, 2007

(C) Japan Antibiotics Research Association

\begin{abstract}
Neoechinulin A, an alkaloid from Eurotium rubrum Hiji025, protected neuronal PC12 cells against cell death induced by peroxynitrite derived from SIN-1 (3-(4morpholinyl)sydnonimine hydrochloride). In this study, we investigated the structure-activity relationships of neoechinulin A and a set of its analogues by using assays to measure anti-nitration and antioxidant activities and cytoprotection against SIN-1-induced PC12 cell death. The presence of the diketopiperazine ring was essential for both the antioxidant and anti-nitration activities of neoechinulin A derivatives. Nevertheless, a derivative lacking the diketopiperazine ring could still protect $\mathrm{PC} 12$ cells against SIN-1 cytotoxicity. An acyclic analogue completely lost the cytoprotective effect while retaining its antioxidant/antinitration activities. Pre-incubation of the cells with neoechinulin A for at least 12 hours was essential for the cells to gain SIN-1 resistance. These results suggest that neoechinulin A endows the cells with cytoprotection through a biological effect different from the apparent antioxidant/anti-nitration activities.
\end{abstract}

Keywords alkaloid, structure-activity relationship, reactive oxygen/nitrogen species, neoechinulin

T. Arai (Corresponding author), K. Kimoto, Y. Shibata, S. Kamisuki, F. Sugawara, K. Kuramochi, K. Kuroiwa, N. Watanabe: Department of Applied Biological Science, Faculty of Science and Technology, 2641 Yamazaki, Noda, Chiba 278-8510, Japan, E-mail: takarai@rs.noda.tus.ac.jp

T. Aoki, A. Nakazaki, S. Kobayashi: Department of Pharmaceutical Sciences, Tokyo University of Science, 2641 Yamazaki, Noda, Chiba 278-8510, Japan

\section{Introduction}

Neoechinulin A (1) is an indole alkaloid and has been isolated by several groups from Aspergillus sp. [1 9], ascomycete Xylaria euglossa [10], and endophytic fungus Chaetomium globosum [11]. The compound is presumably synthesized from an L-tryptophan and an L-alanine, and consists of three structural moieties, an indole, a diketopiperazine, and an isoprenyl moiety. The stereochemistry of the C-8/C-9 double bond, and of the stereocenter $\mathrm{C}-12$, was shown to be $Z$ and $S$, respectively. In the course of our program for the establishment of small molecule library from natural resources, we also isolated this compound from the marine fungus Eurotium rubrum Hiji025, and recently successfully synthesized it with the natural configuration [12].

Reactive oxygen and nitrogen species (ROS/RNS) cause damage to cells. Peroxynitrite $\left(\mathrm{ONOO}^{-}\right)$is one of the most potent RNS generated in biological systems. It is generated from superoxide and nitric oxide at a diffusion-limited rate [13] and can oxidize an array of biomolecules including lipids, proteins, and nucleic acids [14 16]. In addition to being a potent oxidant, peroxynitrite has a unique ability to nitrate tyrosine residues in proteins $[17,18]$. The formation of nitrotyrosines is a hallmark of peroxynitrite formation in vivo. It has been suggested that peroxynitrite plays a role in the pathogenesis of neurodegenerative disorders such as Alzheimer's disease and Parkinson's disease [19 21]. As such, a compound that can prevent neuronal cell death by peroxynitrite has a therapeutic potential for treatment of these diseases. 
1 exhibits antioxidant activities in various assay systems $[7,9]$. Our previous studies also demonstrated that $\mathbf{1}$ could scavenge peroxynitrite generated from SIN-1 (3-(4morpholinyl)sydnonimine hydrochloride) [22]. While the biological activities of the compound remained to be elucidated, we have demonstrated that the treatment with 1 rendered the cells resistant to peroxynitrite cytotoxicity in primary neuronal cells and NGF-differentiated PC12 cells but not in fibroblasts or undifferentiated $\mathrm{PC} 12$ cells [22]. However, the mechanism by which 1 can protect differentiated neuronal cells from SIN-1 cytotoxicity remains unknown.

To gain mechanistic insight into the cytoprotection against peroxynitrite, in the present study we measured the structure-activity relationships of a series of $\mathbf{1}$ derivatives. We examined anti-nitration activity, anti-oxidant activity, and cytoprotective activity against peroxynitrite from SIN-1 in $\mathrm{PC} 12$ cells.

\section{Materials and Methods}

\section{Chemicals and Reagents}

Natural neoechinulins A (1) and B (2) were isolated from Eurotium rubrum Hiji025. Preparation of synthetic 1, entneoechinulin A (3), and $\mathbf{6}$ has been reported, and their purity and stereochemistry were confirmed [12]. 4, 5, and 7 are newly synthesized and fully characterized. Preparation of $\mathbf{4}$ and $\mathbf{7}$ was based on the procedure reported by Izumiya et al. [23]. 5 was prepared from an intermediate in our synthesis of 1 [12]. The isolation of natural neoechinulin $\mathbf{1}$ and $\mathbf{2}$ and the synthesis details and characterization for all analogues will be reported elsewhere (Aoki et al., manuscript in preparation). Stock solutions of these compounds were made in DMSO. Fig. 1 shows the structures of $\mathbf{1}$ and its analogues (2 7) used in the present study.

Hanks balanced salt solution (HBSS) was purchased from Invitrogen (Carlsbad, CA, USA). SIN-1 (3-(4morpholinyl)sydnonimine hydrochlorine), luminol (5amino-2,3-dihydro-1,4-phthalazinedione), and the Kit-8 cell counting kit were purchased from Dojindo (Kumamoto, Japan). Melatonin was purchased from SigmaAldrich (St. Louis, MO, USA). Other chemicals were of analytical grade.

\section{Cell Culture and Treatment}

PC12 cells, a rat pheochromocytoma cell line, were routinely maintained in DMEM containing 5.0\% horse serum, $10 \%$ bovine calf serum, and streptomycin $(100 \mu \mathrm{g} / \mathrm{ml})$ in a humidified atmosphere of $5.0 \% \mathrm{CO}_{2}$ at $37^{\circ} \mathrm{C}$. For experiments with SIN-1, the cells were plated in poly-L-lysine-coated, 96-well culture plates (BD Bioscience, San Jose, CA) or 60-mm dishes at a density of 6,000 cells per $\mathrm{cm}^{2}$. The following day, the cells were treated with NGF $(50 \mathrm{ng} / \mathrm{ml})$ for differentiation in RPMI medium containing $10 \% \mathrm{FCS}$, penicillin $\mathrm{G}(100 \mathrm{U} / \mathrm{ml})$, and streptomycin $(100 \mu \mathrm{g} / \mathrm{ml})$. The medium was changed with fresh medium containing NGF every other day, and on the fourth day the cells were treated with $\mathbf{1}$, or its analogues, for an additional 24 hours. The medium was removed by aspiration, and the cells were exposed to SIN-1

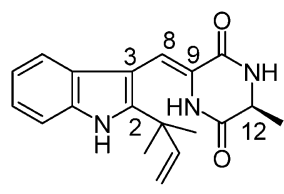

Neoechinulin A (1)

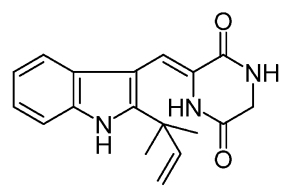

Demethyl-neoechinulin A (4)

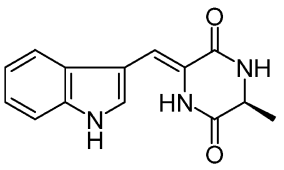

2-Deisoprenyl-neoechinulin A (7)

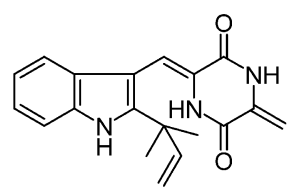

Neoechinulin B (2)

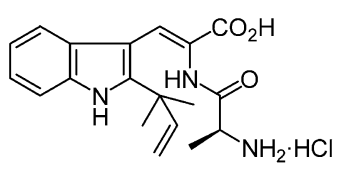

Acyclic analogue (5)

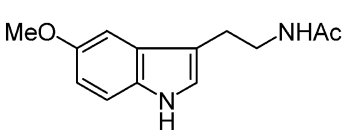

Melatonin (8)

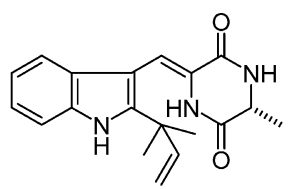

(12R)-Neoechinulin A (3)

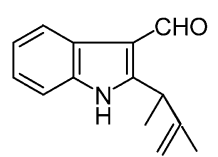

Aldehyde analogue (6)

Fig. 1 Structure of neoechinulin A (1) and its analogues (2 $\sim \mathbf{8})$ used in this study. 
$(1.0 \mathrm{mM})$ in fresh medium for 24 hours.

\section{Cell Viability Assay}

Following SIN-1 treatment, the number of live cells in the wells of plates was counted by using the CyQUEST Cell Proliferation kit according to the instructions provided by the manufacturer (Invitrogen). The fluorescence intensity was measured with a fluorescence plate reader with an excitation wave length at $485 \mathrm{~nm}$ and an emission wave length at $530 \mathrm{~nm}$.

\section{NAD(P)H Dehydrogenase Assay}

$\mathrm{NAD}(\mathrm{P}) \mathrm{H}$ dehydrogenase activities were evaluated by using the kit- 8 cell counting kit (Dojindo). In this assay, the water soluble WST-8 [2-(2-methoxy-4-nitrophenyl)-3(4-nitrophenyl)-5-(2,4-disulphonyl)- $2 H$-tetrazolium] is reduced to its formazan by cellular NADPH or NADH under the catalysis of phenazine methosulfate (PMS) that was added with WST-8. PMS acts as a redox-cycling reagent, resulting in the net transfer of hydride anion from NAD(P)H to WST-8. Therefore, this assay reflects both NADPH and NADH dehydrogenase activities of the cells.

After incubation with $\mathbf{1}$ or its analogues, the medium was replaced with fresh RPMI/FCS medium containing $10 \%$ kit- 8 working solution and incubated for 3 hours. The amounts of formazan were monitored at $450 \mathrm{~nm}$ and were normalized by the number of cells counted by using the CyQUEST Cell Proliferation kit [24].

\section{Nitrotyrosine Assay}

The inhibitory effects on tyrosine nitration by peroxynitrite of $\mathbf{1}$ and its analogues were evaluated according to the methods of Kean et al. [25]. Briefly, test compounds were mixed with BSA $(0.6 \mathrm{mg} / \mathrm{ml})$ in HBSS combined with an equal volume of SIN-1 $(1 \mathrm{mM})$ in the medium and incubated at $37^{\circ} \mathrm{C}$ for 2 hours. Modified BSA was resolved on SDS-PAGE [26] using $4 \mathrm{M}$ urea $-8.0 \%$ acrylamide gel and transferred to PVDF membranes. The level of nitrotyrosine in BSA on the membranes was detected with an anti-nitrotyrosine antibody, followed by a horseradish peroxidase-labeled secondary antibody and chemiluminescence visualization using an ECL kit (GE Healthcare, Little Chalfont, UK) according to the manufacturer's instructions.

\section{Luminol Oxidation Assay}

Antioxidative activity of $\mathbf{1}$ and its analogues with peroxynitrite was evaluated with a luminol chemiluminescence assay, according to the methods of Radi et al. [27]. Briefly, the test compounds in HBSS were plated in a 96-well, white assay plate and mixed with SIN-1
$(0.1 \mathrm{mM})$. Then, luminol $(400 \mu \mathrm{M})$ dissolved in $50 \mathrm{mM}$ sodium bicarbonate was added to each well to give a total volume of $200 \mu \mathrm{l}$. The luminescence signal was recorded for 30 minutes in a microplate luminometer LB96V (PerkinElmer, Waltham, MA, USA), and the total photon counts over the period were used for calculations.

\section{Statistics}

Data are presented as mean \pm S.D. The Student's $t$-test was used to analyze the data. $P$ values less than 0.05 were considered statistically significant.

\section{Results}

\section{Anti-nitration and Antioxidant Activities of Analogues} of 1

We first measured the effect of $\mathbf{1}$ and its derivatives $\mathbf{2} \sim \mathbf{7}$ on nitrotyrosine formation in BSA induced by SIN-1, a peroxynitrite generator [28]. Under the assay conditions, 1 in amounts as low as $22 \mu \mathrm{M}$, completely inhibited nitrotyrosine formation. The inhibitory potency was comparable to that of melatonin (Fig. 2). With the exception of the aldehyde analogue $\mathbf{6}$, all of the $\mathbf{1}$ derivatives showed an inhibitory effect that was similar to

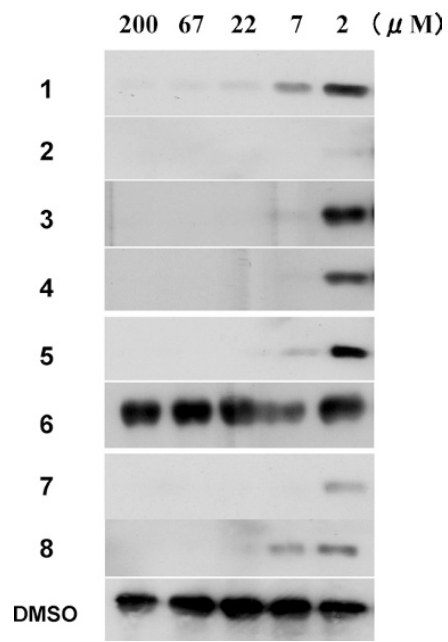

Fig. 2 Effects of $\mathbf{1}$ and its analogues $\mathbf{2} \sim \mathbf{8}$ on nitrotyrosine formation in BSA induced by SIN-1.

BSA was exposed to $\mathrm{SIN}-1$ at $37^{\circ} \mathrm{C}$ for 2 hours in the absence or presence of the indicated concentrations of $\mathbf{1}$ or one of its analogues. Nitrotyrosines in BSA were detected by immunoblotting with an anti-nitrotyrosine antibody. The lowest blot (DMSO) contains the controls for each concentration of test compound, where from the left lane to the right lane, DMSO concentrations were $0.4,0.13,0.044,0.015$, and $0.005 \%$, corresponding to $200,67,22,7$, and $2 \mu \mathrm{M}$ of the test compounds, respectively. 


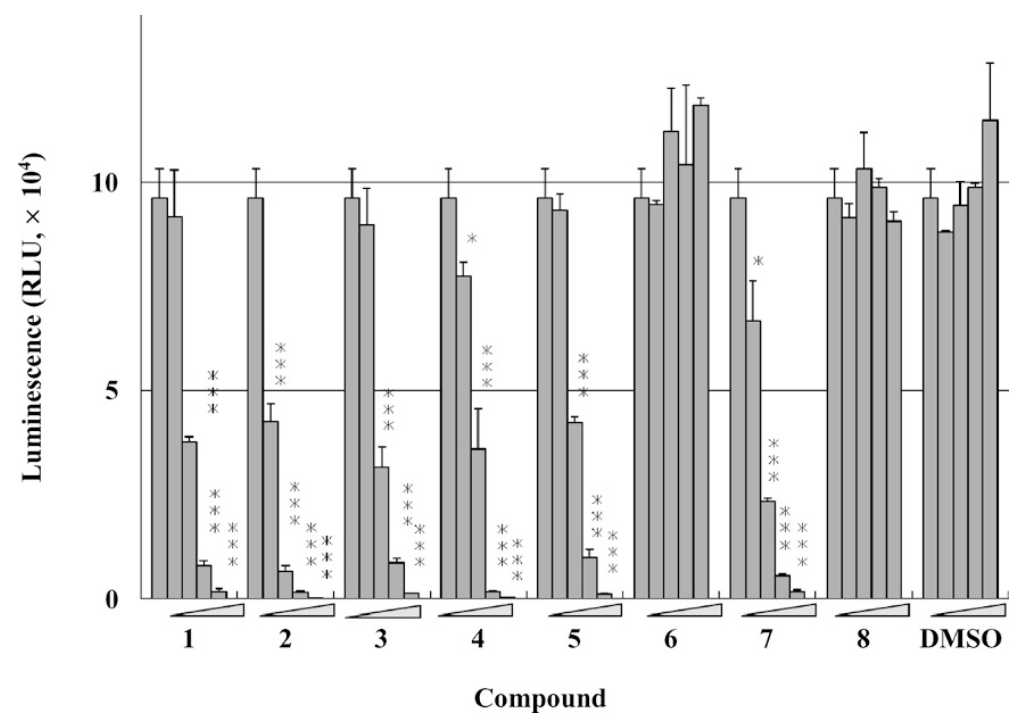

Fig. 3 Effects of $\mathbf{1}$ and its analogues $\mathbf{2} \sim \mathbf{8}$ on luminol oxidation induced by SIN-1.

Photon emission from luminol oxidation by SIN-1 was measured in the presence of increasing concentrations of $\mathbf{1}$ or one of its analogues. Each triangle represents a concentration gradient of the test compounds or DMSO used as a vehicle. The concentrations of the compounds and the corresponding DMSO controls were, from the left side to the right side, $0,12.5,25,50,100,200 \mu \mathrm{M}$ and $0,0.05,0.1$, $0.2,0.4 \%$, respectively. Values are mean \pm S.D. of a representative result conducted in triplicates. ${ }^{*} P<0.05,{ }^{*} P<0.01,{ }^{*} * * P<0.001$.

or more potent than the parental compound; $\mathbf{2}$, even at $2 \mu \mathrm{M}$, completely abrogated nitrotyrosine formation. In contrast, the aldehyde analogue 6, which lacks the diketopiperazine ring, had no inhibitory effect. The order of inhibitory potency was as follows: $2>\mathbf{7}>\mathbf{3}=\mathbf{4}=\mathbf{5}>\mathbf{1}=$ $\mathbf{8} \gg \mathbf{6}$. These results strongly indicate that the presence of an appropriate substitution at $\mathrm{C}-3$ of the indole ring is essential for the inhibitory effect on nitrotyrosine formation induced by SIN-1.

We next measured the antioxidant activity of those compounds in a peroxynitrite-induced luminol oxidation assay (Fig. 3). Due to the presence of bicarbonate in this assay, a significant portion of chemiluminescence emission from luminol oxidation is mediated by secondary oxidizing species such as nitrosoperoxycarbonate $\left(\mathrm{O}=\mathrm{NOOCO}_{2}^{-}\right)$ and carbonate radical $\left(\mathrm{CO}_{3}^{--}\right)$, rather than peroxynitrite itself [27]. Similar to the results of the nitrotyrosine assay, all of the compounds except $\mathbf{6}$ inhibited luminol oxidation induced by SIN-1. Interestingly, however, melatonin did not show any inhibitory effect. The order of inhibitory potency was as follows: $\mathbf{2}>\mathbf{7}>\mathbf{4}>\mathbf{1}=\mathbf{3}=\mathbf{5} \gg \mathbf{8}=\mathbf{6}$. These results suggest that the presence of the conjugated double bond between the indole and diketopiperazine is important for inhibition of luminol oxidation induced by SIN-1.

\section{Cytotoxicity of 1 and Its Analogues}

We first assessed the toxicity of $\mathbf{1}$ and its analogues toward differentiated PC12 cells (Fig. 4). 1 was slightly cytotoxic at concentrations above $100 \mu \mathrm{M}$. Similar degrees of toxicity were observed for all of the other derivatives of $\mathbf{1}$ except $\mathbf{2}$. $\mathbf{2}$ had a much greater toxic effect than did $\mathbf{1}$; the toxicity of 2 became evident even at $12.5 \mu \mathrm{M}$, and more than $50 \%$ of cells were killed at concentrations above $50 \mu \mathrm{M}$.

\section{Neuroprotective Activity of $\mathbf{1}$ and Its Analogues}

We next measured the cytoprotective activity of the compounds against peroxynitrite derived from SIN-1 in the differentiated PC12 cells (Fig. 5A). To evaluate cytoprotection resulting from a biological effect of the compounds, rather than the antioxidant activity, cells were pre-incubated with 1 or its analogues for 24 hours, and then exposed to SIN-1 in a fresh medium for additional 24 hours. As reported previously [22], 1 protected PC12 cells from SIN-1-induced cell death in concentrations analogous to a bell-shaped curve with maximum protection at $100 \mu \mathrm{M} .2$ also demonstrated cytoprotection dosedependently up to $25 \mu \mathrm{M}$; but, above $50 \mu \mathrm{M}$, the protective effect deteriorated. Almost the same degree of protection as $\mathbf{1}$ was observed for other $\mathbf{1}$ derivatives including $\mathbf{3}$ and $\mathbf{7}$. In marked contrast, $\mathbf{5}$, which had inhibited both nitration and oxidation (Figs. 2 and 3), did not protect the cells at all. Thus, the results demonstrate that the intact diketopiperazine ring is essential for the cytoprotective action of the compounds in SIN-1-induced cell death.

To further verify that the cytoprotection was engendered by a biological effect of the compound, cells were pre- 


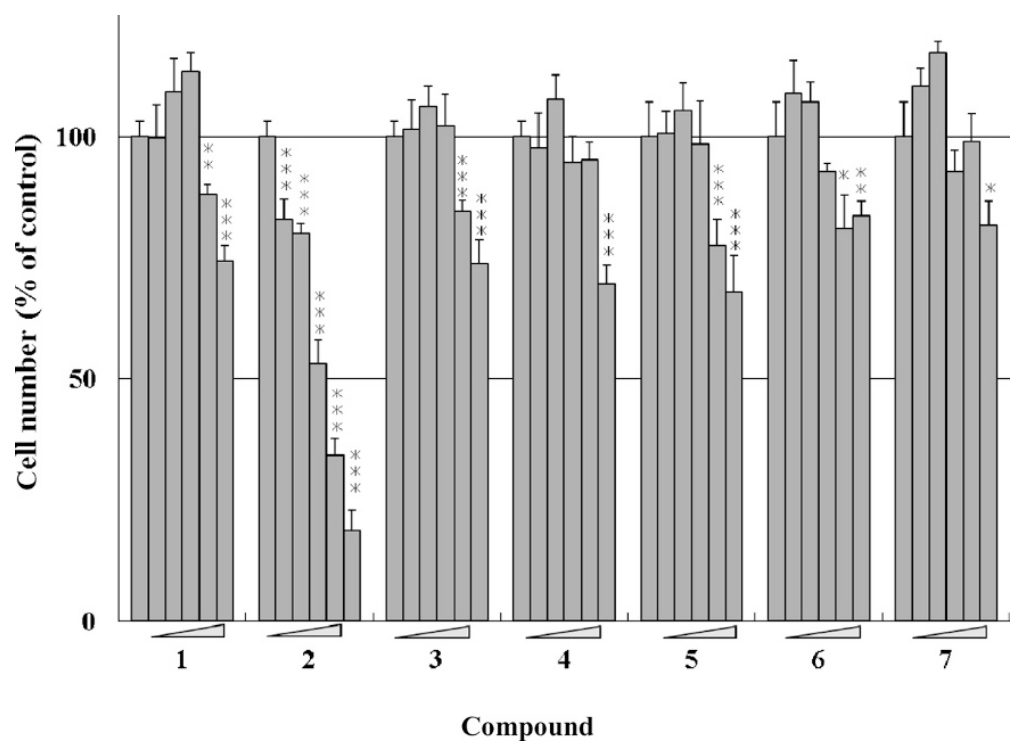

Fig. 4 Cytotoxicity of $\mathbf{1}$ and its analogues $\mathbf{2} \sim \mathbf{7}$.

Cells were incubated with increasing concentrations of $\mathbf{1}$ or one of its analogues $\mathbf{2} \sim \mathbf{7}$ for 24 hours, and the numbers of live cells were counted by the CyQUEST Cell Proliferation kit. Each triangle represents a concentration gradient of $0,12.5,25,50,100$, and 200 $\mu \mathrm{M}$ from the left side to the right side. Values are mean \pm S.D. of a representative result conducted in triplicates. ${ }^{*} P<0.05,{ }^{* *} P<0.01,{ }^{* * *} P<0.001$.

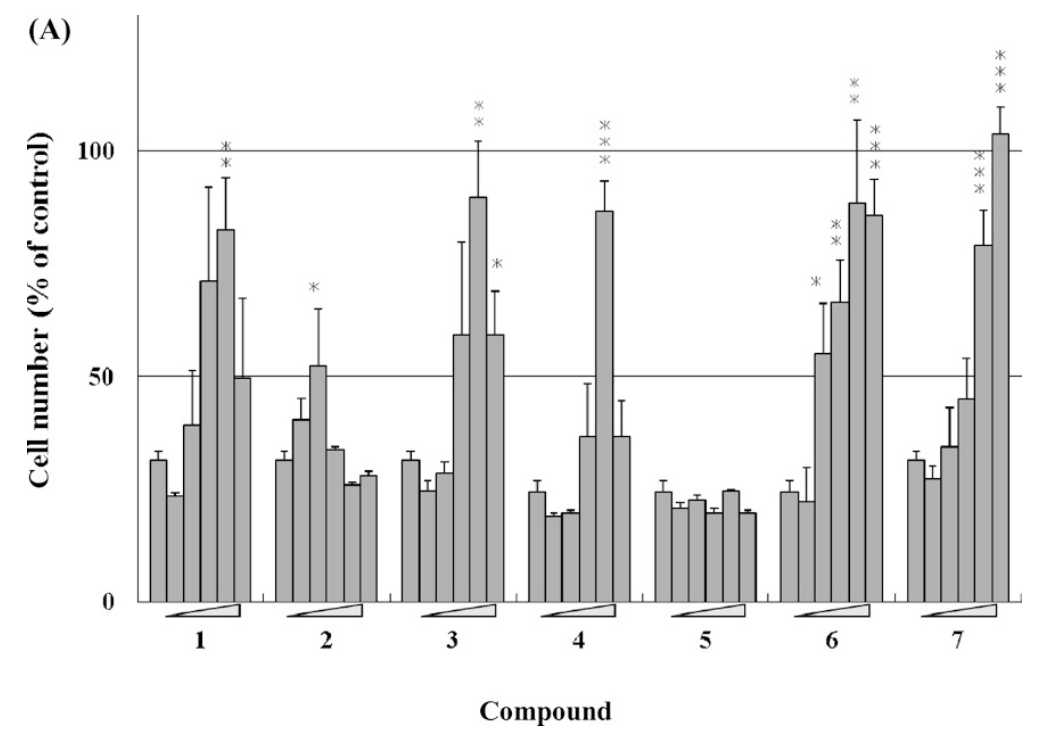

Fig. 5 (A) Cytoprotection of $\mathbf{1}$ and its analogues $\mathbf{2} \sim \mathbf{7}$ against SIN-1 in PC12 cells.

Cells were pre-incubated with increasing concentrations of $\mathbf{1}$ or one of its analogues $\mathbf{2} \sim \mathbf{7}$ for 24 hours and then exposed to $1.0 \mathrm{mM}$ SIN-1 for an additional 24 hours. The numbers of live cells were counted by the CyQUEST Cell Proliferation kit. Each triangle represents a concentration gradient of $0,12.5,25,50,100$, and $200 \mu \mathrm{M}$ from the left side to the right side. Values are mean \pm S.D. of a representative result conducted in triplicate. ${ }^{*} P<0.05, * * P<0.01, * * * 00.001$.

incubated with 1 for various times and then exposed to SIN-1 (Fig. 5B). Resistance to SIN-1 toxicity appeared when the cells were incubated with $\mathbf{1}$ for at least 9 hours, and over $80 \%$ protection could be achieved after a 12 -hours incubation. Thus, we concluded that $\mathbf{1}$ could confer resistance against SIN-1 through a biological action. 


\section{Elevation of NAD(P)H Dehydrogenase Activities by 1 and Its Analogues}

In a previous study, we demonstrated that treatment of PC12 cells for 24 hours with neoechinulin augmented the cellular capability to reduce a water-soluble tetrazolium (WST-8), indicative of $\mathrm{NAD}(\mathrm{P}) \mathrm{H}$ dehydrogenase activity [22]. Therefore, we investigated if the cytoprotective effect

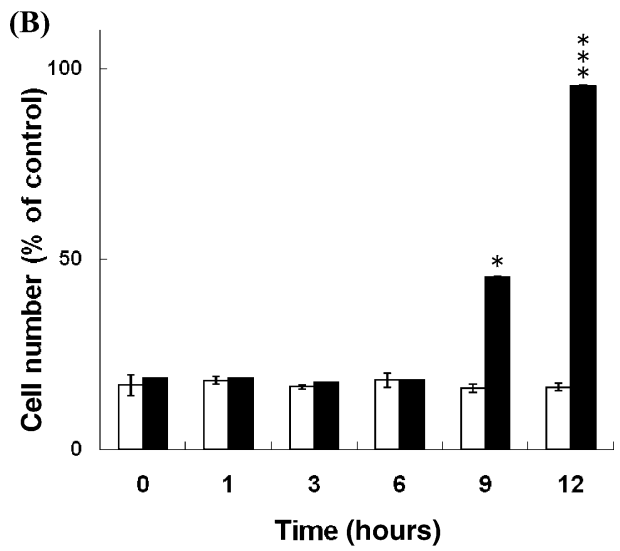

Fig. 5 (B) Effect of pre-incubation time on cytoprotective effect of neoechinulin A against SIN-1.

Cells were pre-incubated with $0.2 \%$ DMSO (open bars) or $100 \mu \mathrm{M}$ of neoechinulin A (1; filled bars) for the indicated time $(0 \sim 12$ hours), and then exposed to $1.0 \mathrm{mM}$ SIN-1. Viability was assessed as described above. Values are mean \pm S.D. of a representative result conducted in triplicate. ${ }^{*} P<0.05,{ }^{* *} P<0.001$. of the compounds against SIN-1 was correlated with the elevated NAD(P)H dehydrogenase activities (Fig. 6). All of the compounds that had shown cytoprotection against SIN1 also increased $\mathrm{NAD}(\mathrm{P}) \mathrm{H}$ dehydrogenase activities with a similar concentration dependency. Consistently, the acyclic 1 analogue 5, which was not cytoprotective, failed to augment $\mathrm{NAD}(\mathrm{P}) \mathrm{H}$ activities. Thus, there was a correlation between cytoprotection and an increase in $\mathrm{NAD}(\mathrm{P}) \mathrm{H}$ dehydrogenase activities of the cells.

\section{Discussion}

The present study revealed the structure-activity relationships of $\mathbf{1}$ and its analogues $2 \sim 7$ with respect to anti-nitration, antioxidant, and cytoprotective activities. The results clearly demonstrate that $\mathbf{6}$, which lacks the diketopiperazine ring of $\mathbf{1}$, exhibits neither anti-nitration nor anti-oxidation activity. Nevertheless, 6 could still protect PC12 cells against peroxynitrite toxicity from SIN1 as could intact $\mathbf{1}$. On the other hand, $\mathbf{5}$ completely lost the cytoprotective activity of $\mathbf{1}$ although its anti-oxidant and anti-nitration activities remained almost the same as those seen for $\mathbf{1}$. Thus, the cytoprotection exerted by $\mathbf{1}$ toward differentiated PC12 cells does not result from the apparent antioxidative or anti-nitrative activities, but is possibly the result of a different biological action of the compounds. In support of this interpretation, at least 12 hours of pre-

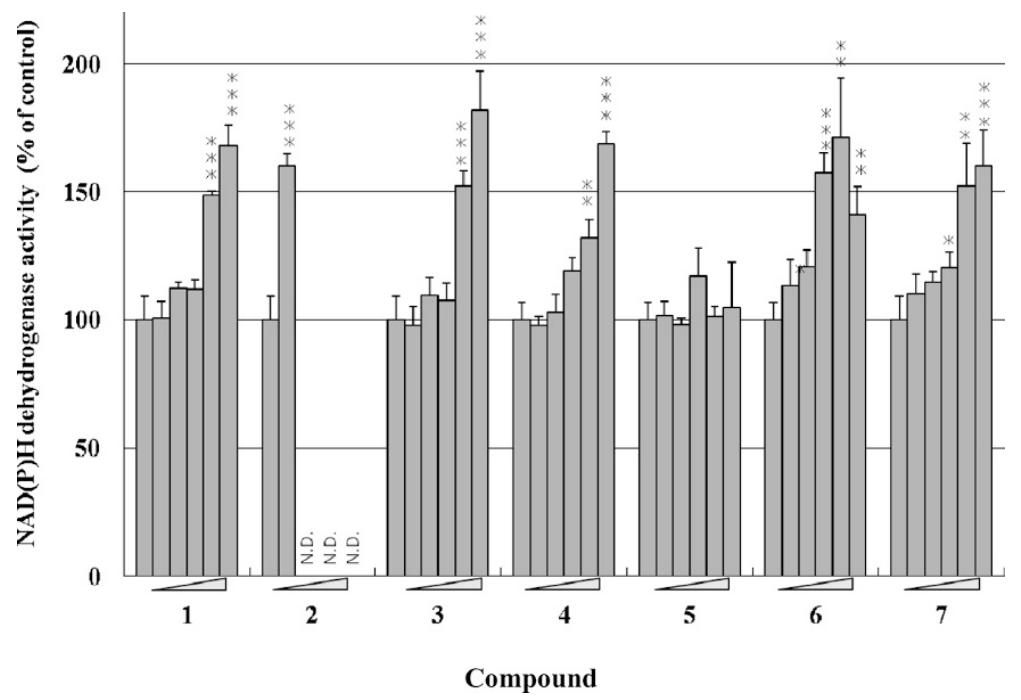

Fig. 6 Effects of $\mathbf{1}$ and its analogues $\mathbf{2} \sim \mathbf{7}$ on NAD(P)H oxidase activity.

Cells were incubated with increasing concentrations of $\mathbf{1}$ or its analogue $\mathbf{2} \sim \mathbf{7}$ for 24 hours. NAD(P)H dehydrogenase activities were measured by kit-8, and the values were normalized by the number of live cells measured using the CyQUEST Cell Proliferation kit. Each triangle represents a concentration gradient of $0,12.5,25,50,100$, and $200 \mu \mathrm{M}$ from the left side to the right side. Values are mean \pm S.D. of a representative result conducted in triplicate. N.D. indicates "not determined" due to severe cytotoxicity. ${ }^{*} P<0.05,{ }^{*} P<0.01$, *** $P<0.001$. 
incubation was required to render cells resistant to SIN-1, suggesting that $\mathbf{1}$ endowed the cells with cytoprotection possibly through the induction of gene expression.

The present study reveals that the cytoprotective activity of these compounds is well correlated with their ability to augment the NAD(P)H-producing capacity of the cells. However, it is not yet clear which $\mathrm{NAD}(\mathrm{P}) \mathrm{H}$-generating dehydrogenase(s) of cells, namely, dehydrogenase(s) of the glycolytic pathway, the Krebs cycle, and/or the pentose phosphate pathway, etc., are responsible for the elevation. However, many cellular antioxidant enzyme systems, including glutathione peroxidases and peroxiredoxins, utilize NADPH as a reducing equivalent to detoxify hydrogen peroxide and lipid hydroperoxides [29, 30]. A recent study demonstrated that peroxiredoxins can also reduce peroxynitrite using NADPH [31]. The activity of pentose phosphate pathway enzymes, glucose 6-phosphate dehydrogenase and 6-phosphogluconate dehydrogenase, is a critical factor for the sensitivity to oxidative stresses [32, 33]. Besides the pentose phosphate pathway, $\mathrm{NADP}^{+}$dependent isocitrate dehydrogenases also generate $\mathrm{NADPH}$, and their activities are crucial for cells to survive under oxidative stresses $[34,35]$. It may be possible that 1 can induce the expression of those enzymes or their positive regulators, thereby fortifying the cells against peroxynitrite insults. We are now investigating this possibility.

In conclusion, the present study reveals that $\mathbf{1}$ and its analogues confer cytoprotection against peroxynitrite to PC12 cells, possibly through potentiation of the cellular $\mathrm{NAD}(\mathrm{P}) \mathrm{H}$-producing capacity in a mechanism independent of antioxidative/anti-nitration activities. Thus, these compounds have a therapeutic potential for the treatment of neurodegenerative diseases and chronic inflammatory diseases in which peroxinitrite is a deteriorating factor.

Acknowledgement This work was supported by grants from the Promotion and Mutual Aid Corporation for Private Schools of Japan, and Research on Advanced Medical Technology from the Ministry of Health, Labor and Welfare of Japan.

\section{References}

1. Casnati G, Pochini P, Ungaro R. Neoechinulin: A new isoprenyl indole metabolite from Aspergillus amstelodami Grazz. Chim Ital 103: 141-151 (1972)

2. Itokawa H, Akita Y, Yamazaki M. The indole derivatives isolated from the oil cakes of camellia seeds. On the relation to the components of the fungus infecting the oil cakes. Yakugaku Zasshi 93: 1251-1252 (1973)
3. Dossena A, Marchelli R, Pochini A. New metabolites of Aspergillus amstelodami related to the biogenesis of neoechinulin. J Chem Soc Chem Commun 771-772 (1974)

4. Marchelli R, Dossena A, Casnati G. Biosynthesis of neoechinulin by Aspergillus amstelodami from cyclo-L-[U14C]-L-[5,7-3H2]tryptophyl. J Chem Soc Chem Commun 779-780 (1975)

5. Nagasawa H, Isogai A, Ikeda K, Sato S, Murakoshi S, Suzuki A, Tamura S. Isolation and structure elucidation of a new indole metabolite from Aspergillus ruber. Agr Biol Chem 39: 1901-1902 (1975)

6. Marchelli R, Dossena A, Pochini A, Dradi E. The structures of five new didehydropeptides related to neoechinulin, isolated from Aspergillus amstelodami. J Chem Soc Perkin Trans 1 713-717 (1977)

7. Yagi R, Doi K. Isolation of an antioxidative substance produced by Aspergillus repens. Biosci Biotech Biochem 63: 932-933 (1999)

8 Li Y, Li X, Kang JS, Choi HD, Son BW. New radical scavenging and ultraviolet-A protecting prenylated dioxopiperazine alkaloid related to isoechinulin A from a marine isolate of the fungus Aspergillus. J Antibiot 57: 337-340 (2004)

9. Li Y, Li X, Kim SK, Kang JS, Choi HD, Rho JR, Son BW. Golmaenone, a new diketopiperazine alkaloid from the marine-derived fungus Aspergillus sp. Chem Pharm Bull 52: 375-376 (2004)

10. Wang XN, Tan RX, Liu JK. Xylactam, a new nitrogencontaining compound from the fruiting bodies of ascomycete Xylaria euglossa. J Antibiot 58: 268-270 (2005)

11. Wang S, Li X-M, Teuscher F, Li D-L, Diesel A, Ebel R, Proksch P, Wang B-G. Chaetopyranin, a benzaldehyde derivative, and other related metabolites from chaetomium globosum, an endophytic fungus derived from the marine red alga Polysiphonia urceolata. J Nat Prod 69: 1622-1625 (2006)

12. Aoki T, Kamisuki S, Kimoto M, Ohnishi K, Takakusagi Y, Kuramochi K, Takeda Y, Nakazaki A, Kuroiwa K, Ohuchi T, Sugawara F, Arai T, Kobayashi S. Total synthesis of (-)neoechinulin A. Synlett 5: 677-680 (2006)

13. Beckman JS, Beckman TW, Chen J, Marshall PA, Freeman BA. Apparent hydroxyl radical production by peroxynitrite: implications for endothelial injury from nitric oxide and superoxide. Proc Natl Acad Sci USA 87: 1620-1624 (1990)

14. Darley-Usmar VM, Hogg NO, Leary VJ, Wilson MT, Moncada S. The simultaneous generation of superoxide and nitric oxide can initiate lipid peroxidation in human low density lipoprotein. Free Radic Res Commun 17: 9-20 (1992)

15. Salgo MG, Bermudez E, Squadrito GL, Pryor WA. Peroxynitrite causes DNA damage and oxidation of thiols in rat thymocytes. Arch Biochem Biophys 322: 500-505 (1995)

16. Radi R, Beckman JS, Bush KM, Freeman BA. Peroxynitriteinduced membrane lipid peroxidation: the cytotoxic 
potential of superoxide and nitric oxide. Arch Biochem Biophys 288: 481-487 (1991)

17. Ischiropoulos $\mathrm{H}$, al-Mehdi AB. Peroxynitrite-mediated oxidative protein modifications. FEBS Lett 364: 279-282 (1995)

18. Van der Viiet AO, Neill CA, Halliwell B, Cross CE, Kaur H. Aromatic hydroxylation and nitration of phenylalanine and tyrosine by peroxynitrite. Evidence for hydroxyl radical production from peroxynitrite. FEBS Lett 39: 89-92 (1994)

19. Good PF, Hsu A, Werner P, Perl DP, Olanow CW. Protein nitration in Parkinson's disease. J Neuropathol Exp Neurol 57: 338-342 (1998)

20. Smith MA, Richey Harris PL, Sayre LM, Beckman JS, Perry G. Widespread peroxynitrite-mediated damage in Alzheimer's disease. J Neurosci 17: 2653-2657 (1997)

21. Good PF, Werner P, Hsu A, Olanow CW, Perl DP. Evidence of neuronal oxidative damage in Alzheimer's disease. Am J Pathol 149: 1-28 (1996)

22. Maruyama K, Ohuchi T, Yoshida K, Shibata Y, Sugawara F, Arai T. Protective properties of neoechinulin A against SIN1-induced neuronal cell death. J Biochem (Tokyo) 136: 81-87 (2004)

23. Kanmera $\mathrm{T}$, Lee $\mathrm{S}$, Aoyagi H, Izumiya N. Efficient asymmetric syntheis of $\alpha$-amino acids through hydrogenation of $\alpha, \beta$-dehydroamino acid residue in cyclic dipeptides. Tetrahedron Lett 46: 4483-4486 (1979)

24. Ishiyama M, Tominaga H, Shiga M, Sasamoto K, Ohkura Y, Ueno K. A combined assay of cell viability and in vitro cytotoxicity with a highly water-soluble tetrazolium salt, neutral red and crystal violet. Biol Pharm Bull 19: 1518-1520 (1996)

25. Kean RB, Spitsin SV, Mikheeva T, Scott GS, Hooper DC. The peroxynitrite scavenger uric acid prevents inflammatory cell invasion into the central nervous system in experimental allergic encephalomyelitis through maintenance of bloodcentral nervous system barrier integrity. J Immunol 165: 6511-6518 (2000)

26. Laemmli UK. Cleavage of structural proteins during the assembly of the head of bacteriophage T4. Nature 227: 680-685 (1970)
27. Radi R, Cosgrove TP, Beckman JS, Freeman BA. Peroxynitrite-induced luminol chemiluminescence. Biochem J 290: 51-57 (1993)

28. Feelish M, Ostrowski J, Noack E. On the mechanism of NO release from sydnonimines. J Cardiovasc Parmacol 14: S13-S22 (1989)

29. Dringen R, Pawlowski PG, Hirrlinger J. Peroxide detoxification by brain cells. J Neurosci Res 79: 157-165 (2005)

30. Rhee SG, Chae HZ, Kim K. Peroxiredoxins: a historical overview and speculative preview of novel mechanisms and emerging concepts in cell signaling. Free Radic Biol Med 38: 1543-1552 (2005)

31. Ogusucu R, Rettori D, Munhoz DC, Netto LE, Augusto O. Reactions of yeast thioredoxin peroxidases I and II with hydrogen peroxide and peroxynitrite: rate constants by competitive kinetics. Free Radic Biol Med 42: 326-334 (2007)

32. Tian WN, Braunstein LD, Apse K, Pang J, Rose M, Tian X, Stanton RC. Importance of glucose-6-phosphate dehydrogenase activity in cell death. Am J Physiol 276: C1121-C1131 (1999)

33. Filosa S, Fico A, Paglialunga F, Balestrieri M, Crooke A, Verde P, Abrescia P, Bautista JM, Martini G. Failure to increase glucose consumption through the pentosephosphate pathway results in the death of glucose-6phosphate dehydrogenase gene-deleted mouse embryonic stem cells subjected to oxidative stress. Biochem J 370 (Pt. 3): 935-943 (2003)

34. Maeng O, Kim YC, Shin HJ, Lee JO, Huh TL, Kang KI, Kim YS, Paik SG, Lee H. Cytosolic NADP(+)-dependent isocitrate dehydrogenase protects macrophages from LPSinduced nitric oxide and reactive oxygen species. Biochem Biophys Res Commun 317: 558-564 (2004)

35. Jo SH, Son MK, Koh HJ, Lee SM, Song IH, Kim YO, Lee YS, Jeong KS, Kim WB, Park JW, Song BJ, Huh TL. Control of mitochondrial redox balance and cellular defense against oxidative damage by mitochondrial NADP+dependent isocitrate dehydrogenase. J Biol Chem 276: 16168-16176 (2001) 